\title{
Fungal biocatalysts in the biofiltration of VOC-polluted air
}

Christian Kennes, María C. Veiga

Journal of Biotechnology, Volume 113, Issues 1-3, 30 September 2004, Pages 305-319

DOI: 10.1016/j.jbiotec.2004.04.037

\begin{abstract}
Gas-phase biofilters used for the treatment of waste gases were originally packed with compost or other natural filter beds containing indigenous microorganisms. Over the past decade much effort has been made to develop new carrier materials, more performant biocatalysts and new types of bioreactors. Elimination capacities reached nowadays are 5 to 10 times higher than those originally reported with conventional compost biofilters. With the recently developed inert filter beds, inoculation is a prerequisite for successful start-up and operation. Either non-defined mixed cultures or pure bacterial cultures have originally been used. The search for efficient fungal biocatalysts started only a few years ago, mainly for the biofiltration of waste gases containing hydrophobic compounds, such as styrene, $\alpha$-pinene, benzene, or alkylbenzenes. In this review, recently isolated new fungal strains able to degrade alkylbenzenes and other related volatile organic pollutants are described, as well as their major characteristics and their use as biocatalysts in gas-phase biofilters for air pollution control. In biofiltration, the most extensively studied organism belongs to the genus Exophiala, although strains of Scedosporium, Paecilomyces, Cladosporium, Cladophialophora, and white-rot fungi are all potential candidates for use in biofilters. Encouraging results were obtained in most of the cases in which some of those organisms were present in gas-phase biofilters. They allow reaching high elimination capacities and are resistant to low $\mathrm{pH}$ values and to reduce moisture content.
\end{abstract}

\section{Keywords}

Air pollution control; Exophiala sp.; Filamentous fungi; Odours; Volatile organic compound; White-rot fungi 


\section{Background on the biodegradation of volatile pollutants by fungi}

The biodegradation of volatile pollutants by fungi in batch liquid cultures was already reported a few decades ago mainly in the case of not only aliphatic compounds, such as $n$-alkanes, but also alcohols, formaldehyde, etc.; as well as in the case of hydroxylated aromatics, i.e. phenols. Some examples are listed in Table 1. However, extensive studies on the removal of volatile compounds belonging to the group of non-oxygenated aromatic pollutants, i.e. benzene, alkylbenzenes, styrene, and other related compounds, by filamentous fungi and yeast-like fungi were initiated only very recently. Assimilation of such compounds seems not to be a widespread characteristic in eukaryotes.

Table 1. Biodegradation and growth of filamentous fungi on some volatile aliphatics and phenolic pollutants

\begin{tabular}{|c|c|c|}
\hline Compounds & Organisms & References \\
\hline \multicolumn{3}{|l|}{ n-Alkanes } \\
\hline $\mathrm{C}_{2}$ - $\mathrm{C}_{4}$-Alkanes & Acremonium sp. & Davies et al. (1973) \\
\hline \multirow[t]{2}{*}{$\mathrm{C}_{6}-\mathrm{C}_{19}$-Alkanes } & Cladosporium resinae & Cofone et al. (1973) \\
\hline & ATCC 22711 & \begin{tabular}{|l} 
Lindley and Heydeman \\
$(1983)$
\end{tabular} \\
\hline$n$-Butane & Graphium sp. ATCC 58400 & Hardison et al. (1997) \\
\hline $\mathrm{C}_{1}-\mathrm{C}_{9}$-Alkanes & Scedosporium sp. & Onodera et al. (1989a) \\
\hline$n$-Hexadecane & Trichosporon veenhuisii CBS 7136 & Middelhoven et al. (2000) \\
\hline \multicolumn{3}{|l|}{ Phenols } \\
\hline Phenol & Aspergillus japonicus & Milstein et al. (1983) \\
\hline \multirow[t]{2}{*}{ Phenol } & Penicillium spp. & Scow et al. (1990) \\
\hline & & Hofrichter et al. (1993) \\
\hline Phenol & Trichosporon cutaneum & $\begin{array}{|lll|}\begin{array}{l}\text { Neujahr } \\
(1970)\end{array} & \text { and } & \text { Varga } \\
\end{array}$ \\
\hline \begin{tabular}{|l|} 
Phenol \\
\end{tabular} & Trichosporon guehoae CBS & Middelhoven et al. (1999) \\
\hline m-Cresol & 8521 & \\
\hline Phenol & Trichosporon veenhuisii & Middelhoven et al. (2000) \\
\hline$m$-Cresol & CBS 7136 & \\
\hline$p$-Cresol & Aspergillus fumigatus ATCC 28282 & Jones et al. (1993) \\
\hline o-Cresol & $\begin{array}{l}\begin{array}{l}\text { Penicillium frequentans ATCC } 96048{ }^{\text {a }} \text { (growth on } \\
\text { glucose and phenol) }\end{array} \\
\end{array}$ & Hofrichter et al. (1995) \\
\hline$o, m$, and $p$-Cresol & Trichosporon cutaneum KUY-6A & Hasegawa et al. (1990) \\
\hline \multicolumn{3}{|l|}{ Others } \\
\hline \begin{tabular}{|l|} 
Formaldehyde \\
\end{tabular} & Gliocladium deliquesecens & Sakaguchi et al. (1975) \\
\hline \multicolumn{3}{|l|}{ Methanol } \\
\hline \begin{tabular}{|l|} 
Formaldehyde \\
\end{tabular} & Paecilomyces variotii & Sakaguchi et al. (1975) \\
\hline \multicolumn{3}{|l|}{ Methanol } \\
\hline Diethyl ether & Graphium sp. ATCC 58400 & Hardison et al. (1997) \\
\hline $\begin{array}{|ll|}\begin{array}{l}\text { Methyl } \\
\text { ether }\end{array} & \text { tert-butyl } \\
\end{array}$ & Graphium sp. ATCC $58400^{\text {a }}$ (growth on $n$-alkanes) & Hardison et al. (1997) \\
\hline
\end{tabular}

A Cometabolism. 
The strain Cladosporium resinae ATCC 22711 was claimed to exhibit a minimal growth with a low biomass yield on benzene after a long period of incubation of several weeks, but further investigation with that strain would have been needed to confirm this finding ( Cofone et al., 1973). More recently, Phanerochaete chrysosporium was also shown to use and degrade 9.6 and 18.1\% benzene in the case of strains ME-446 and BKM-F 1767, respectively ( Yadav and Reddy, 1993). Somewhat more information has recently been obtained on the biodegradation of substituted benzenes in fungi. A recent study showed that among 260 fungi screened from a culture collection, none appeared to be able to grow on toluene as sole carbon and energy source ( Prenafeta-Boldú et al., 2001). Despite this observation, experiments with new fungal isolates indicated that toluene seems to be the most easily biodegradable alkylbenzene in fungi ( Estévez et al., 2004, García-Peña et al., 2001, Prenafeta-Boldú et al., 2001 and Woertz et al., 2001). According to our present knowledge, fungi using xylenes as carbon and energy sources are scarce. Some strains of the white-rot fungus $P$. chrysosporium can degrade xylenes during primary metabolism, although biodegradation is only partial $(<50 \%)$ and the level of mineralization is quite limited ( Yadav and Reddy, 1993). Very recently xylenes proved to be partly cometabolized by another fungal strain, that does not belong to the group of white-rot fungi, in presence of toluene or ethylbenzene as growth substrate ( Prenafeta-Boldú et al., 2002). Benzene rings with one single side chain seem to be much easier to metabolize than poly-substituted compounds in eukaryotes. The same is true in most prokaryotes ( Veiga et al., 1999). However, some fungi appeared to degrade $n$ alkylbenzenes with side chains containing at least four or more carbons, while they were unable to grow on benzene, toluene or ethylbenzene ( Fedorak and Westlake, 1986). Although fungi can degrade volatile aromatic pollutants, the capacity to degrade hydrocarbons is not a constant characteristic among specific fungal species, and such metabolic activity can therefore not be used in taxonomic studies ( Oudot et al., 1993), despite the fact that this has sometimes been suggested ( Nyns et al., 1968). In this paper, our interest will mainly focus on the group of alkyl- and alkenyl-benzenes, since they are important air pollutants and most of the information on the removal of those compounds by fungi is very recent. Studies on the removal of such hydrophobic compounds from polluted air by means of gas-phase bioreactors inoculated with fungi or yeast-like fungi were initiated hardly more than one decade ago ( Braun-Lüllemann et al., 1992, Cox et al., 1996a and Cox et al., 1997).

\section{Suitability of fungi for air treatment in biofilters}

\subsection{Potential advantages of fungal biofilters}

The main advantage of fomenting fungal rather than bacterial growth for the biofiltration of hydrophobic pollutants is their ability to degrade the substrates under extreme environmental conditions regarding $\mathrm{pH}$, low water content and limited nutrient concentrations.

Fungi are able to grow under both neutral as well as acidic conditions and to be metabolically active over a wide $\mathrm{pH}$ range between approximatly 2 and 7, depending on the species. Bacteria are usually considered to be less tolerant to $\mathrm{pH}$ fluctuations and require a near neutral environment for their activity. Occasionally, some bacterial species do also tolerate acidic conditions and may outcompete fungi in acidic environments. This is the case for several organic and inorganic sulphur-compounds. Indeed, bacterial biodegradation of pollutants as hydrogen sulphide or dimethyl 
sulphide generates acids causing a strong acidification of the medium (Kennes and Veiga, 2001). Bacteria degrading such compounds remain highly active down to $\mathrm{pH}$ values as low as 1 or 2 (Yang and Allen, 1994). Biodegradation of sulphur-compounds by fungi is also possible, although it is apparently much less common among eukaryotes than among bacteria (Ishikawa et al., 1980 and Phae and Shoda, 1991), and fungi degrading such pollutants are often not active at very low $\mathrm{pH}$. An unidentified basidiomycete appeared to degrade hydrogen sulphide, methanethiol, dimethyl sulphide and dimethyl disulphide at high rates between $\mathrm{pH} 5.6$ and 6.9 (Phae and Shoda, 1991). However, extremely low rates were measured with that strain at either $\mathrm{pH} 3.8$ or $\mathrm{pH} 7.5$. Some examples of microorganisms degrading sulphur-compounds are listed in Table 2.

Table 2. Examples of microorganisms degrading hydrogen sulphide and dimethyl disulphide

\begin{tabular}{||l|l|l|l||}
\hline Compounds & Microorganisms & Other characteristic & References \\
\hline \hline Hydrogen sulphide & Thiobacillus sp. CH11 & Autotrophic & Chung and Huang (1997) \\
\hline & Thiobacillus thioparus TK-m & Autotrophic & Tanji et al. (1989) \\
\hline & Thiobacillus thiooxidans KS1 & Autotrophic & Shinabe et al. (1995) \\
\hline & Hyphomicrobium sp. I55 & Methylotrophic & Zhang et al. (1991a) \\
\hline & Xanthomonas sp. DY44 & Heterotrophic & Cho et al. (1992) \\
\hline \hline & Unidentified basidiomycete & Fungus & Phae and Shoda (1991) \\
\hline \hline & Cephalosporium sp. & Fungus & Ishikawa et al. (1980) \\
\hline \hline Dimethyl disulphide & Thiobacillus sp. & Autotrophic & Kelly and Smith (1990) \\
\hline \hline & Hyphomicrobium sp. I55 & Methylotrophic & Zhang et al. (1991a) \\
\hline \hline & Pseudomonas acidovorans DMR11 & Heterotrophic & Zhang et al. (1991b) \\
\hline \hline & Unidentified basidiomycete & Fungus & Phae and Shoda (1991) \\
\hline \hline & Cephalosporium sp. & Fungus & Ishikawa et al. (1980) \\
\hline
\end{tabular}

Somewhat more different fungal species can degrade volatile organic compounds (VOCs) under extreme conditions and would be particularily useful for biological waste gas treatment. Occasionally, some bacterial strains are also efficient VOC degraders in acid media, and some Pseudomonas and Bacillus strains can degrade alkylbenzenes at low $\mathrm{pH}$ (around $\mathrm{pH}$ 3.5), although such characteristic is not really widespread among prokaryotes ( Veiga et al., 1999).

It is well known that when treating waste gases in gas-phase bioreactors, a major concern is to maintain a high enough level of moisture to avoid a drop of performance (Kennes and Veiga, 2001). Here again, fungi present another advantage over bacteria, in that they are more tolerant to a low water content and a reduced water activity. The water activity $\left(a_{\mathrm{w}}\right)$ is the amount of water that is free in a given environment. Contrary to the water content, the value of $a_{\mathrm{w}}$ represents the amount of water actually available to microorganisms. For pure distilled water, $a_{\mathrm{w}}=1.0$. If chemicals or solids are added to an aqueous phase, the water activity will usually drop below 1 . For optimal growth of most bacteria, the water activity should be above 0.90 , while xerotolerant fungi are capable of growing at $a_{\mathrm{w}}$ values as low as 0.60 . Exceptionally, bacteria do also tolerate or require low water activities for growth, as was observed for some Bacillus ( $a_{\mathrm{w}}=$ $0.90)$, Staphylococcus $\left(a_{\mathrm{w}}=0.85\right)$ or Halobacterium $\left(a_{\mathrm{w}}=0.75\right)$ species ( Atlas and Bartha, 1998). 
It has recently been suggested that fungi may be especially suitable for the treatment of waste gases containing hydrophobic pollutants. It was hypothesized that the large surface area of hyphae would enhance the absorption and transport of hydrophobic compounds from the contaminated gas phase to the cell surface (Kennes and Veiga, 2001). Also, fungi are more tolerant to dry conditions than bacteria. Therefore, the thickness of the water layer between the gas phase and the fungal biofilm may be smaller, which, here again, results in a faster mass transfer of hydrophobic compounds from the air to the biocatalyst. However, this does not necessarily mean that the presence of filamentous fungi will always allow reaching a higher biofilter performance than with other types of microorganisms, since other parameters will also affect the removal rate and the efficiency of biodegradation.

\subsection{Potential drawbacks of fungal biofilters}

As a matter of fact, the growth of fungi in biofilters does not only present advantages. The most relevant potential drawbacks are explained hereafter.

High head losses are reached sooner in presence of filamentous fungi than in the presence of non-filamentous microorganisms, eventually leading to channeling and clogging problems in the biofilter, which ends up in a reduced efficiency. Recently, some innovative solution, such as the addition of mites to the filter bed has been tested to reduce such problem (van Groenestijn et al., 2001). Other methods, as backwashing or air-sparging, as well as the use of specific chemicals, may be used to control the pressure drop (Mendoza et al., 2004).

The potential pathogenicity of some fungi found in biofilters is another problem, above all in the case of strains presenting a fast growth around $37^{\circ} \mathrm{C}$. However, one should also keep in mind that many fungi are not pathogenic at all and do not cause diseases in healthy persons. Some yeasts and fungi have even proven to be very useful to human beings for ages.

Finally, according to our present knowledge of fungal metabolism of hydrophobic pollutants, in general, fungi grow on a somewhat narrower range of substrates than bacteria, which may limit their application to waste gases containing only a reduced number of different pollutants. Otherwise, mixed cultures may be required for the treatment of complex gaseous effluents. Regarding the range of temperatures suitable for biofiltration with fungi, it is worth mentioning that fungal biofiltration under thermophilic conditions remains an unexplored area of research. Most fungi degrading volatile hydrophobic pollutants have been isolated under mesophilic conditions.

\section{Fungal candidates for VOC removal and air pollution control}

As mentioned above, theoretically filamentous fungi and yeast-like fungi are best suited for the treatment of hydrophobic VOCs rather than volatile inorganic compounds (VICs), organic sulphur-compounds, or other related pollutants. So far, they have almost exclusively been inoculated in biofilters fed non-oxygenated benzene related pollutants. Our review will thus mainly focus on these contaminants, although it would certainly be worth evaluating the efficiency of such microorganisms in presence of other aromatic as well as aliphatic compounds, and above all in case of mixtures of different 
pollutants. The present section will focus on the few fungi that have been either isolated from gas-phase biofilters or inoculated in such systems.

\subsection{Ligninolytic fungi}

The biodegradation of toxic contaminants by ligninolytic fungi has been studied for several decades mainly in polluted soils and, to a lower extent, in wastewaters. By far, the most widely studied white-rot fungus belongs to the species $P$. chrysosporium. Although, the interest of inoculating ligninolytic fungi in gas-phase biofilters has been evaluated, these organisms are mainly interesting for the removal of high-molecularweight aromatic compounds rather than volatile pollutants ( Cerniglia, 1992). Therefore, they are best suited for soil remediation ( Davis et al., 1993) rather than for air pollution control. As their name indicates, ligninolytic fungi are able to degrade complex molecules as lignin. The stimulation of the ligninolytic metabolism of white-rot basidiomycetes results in the expression of extracellular enzymes. These enzymes are highly non-specific and allow the biodegradation of pollutants as polyaromatic hydrocarbons (PAHs) or other aromatic compounds with a structure similar to lignin regions. It is worth mentioning that some bacteria can also degrade low-molecularweight PAHs, in most cases, at higher rates than white-rot fungi, but they are less resistant to extreme conditions regarding $\mathrm{pH}$ or water content. Lighter molecules, such as the pollutants belonging to the BTEX family (benzene, toluene, ethylbenzene, xylenes) as well as styrene can also be biodegraded by $P$. chrysosporium and some other white-rot fungi ( Yadav and Reddy, 1993 and Braun-Lüllemann et al., 1997).

There are a few drawbacks linked to the use of basidiomycetes. Besides the need of macronutrients, a primary carbon and energy source must be added for the removal of most pollutants, since biodegradation of many VOCs results from a cometabolic mechanism. Therefore, a primary substrate must often be added to the contaminated environment if not naturally available in the system. In general, the production of ligninolytic enzymes occurs under nutrient (usually nitrogen) limitation, but, occasionally, the biodegradation system may be expressed during primary metabolism for some pollutants. This is the case for BTEX compounds, which are degraded under non-ligninolytic culture conditions in P. chrysosporium ME-446 and BKM-F 1767 ( Yadav and Reddy, 1993). Biodegradation does not thus involve extracellular lignin peroxidases nor manganese-dependent peroxidases.

Another potential disadvantage of white-rot fungi is the accumulation of significant amounts of toxic intermediate products (Kennes and Lema, 1994), although the complete mineralization of a fraction of some pollutants to carbon dioxide has sometimes been reported, reaching occasionally up to 50\% mineralization in the case of a P. chrysosporium strain fed toluene ( Yadav and Reddy, 1993). Biodegradation of styrene by the white-rot fungus Pleurotus ostreatus led to the formation of phenyl-1, 2ethanediol, 2-phenylethanol and benzoic acid, while only 4\% of the original substrate concentration was recovered as carbon dioxide according to experiments with ${ }^{14} \mathrm{C}$ labelled compounds ( Braun-Lüllemann et al., 1997). The same authors report the complete removal of styrene in $48 \mathrm{~h}$ by $P$. chrysosporium ATCC 34541 at $22^{\circ} \mathrm{C}$ and $\mathrm{pH}$ 5.5. More recent studies showed that another strain, $P$. chrysosporium ATCC 24725 , was unable to grow on styrene at ambient temperature $\left(23 \pm 2{ }^{\circ} \mathrm{C}\right)$ between $\mathrm{pH} 3.5$ and 6.5 ( Qi et al., 2002). 


\subsection{Exophiala spp.}

Exophiala species belong to the so-called group of black yeasts. They present either a yeast-like shape or a filamentous morphology with the formation of hyphae. Some Exophiala strains are prone to cause cutaneous infections, but basically exclusively in non-healthy persons. Their potential for biodegradation of VOCs was discovered quite recently. Studies undertaken with 84 benzene-related compounds and 28 yeasts and yeast-like species have shown that growth on oxygenated aromatic substrates is more frequent among basidomycetous yeast species than among ascomycetes. However, the most outstanding exception in that study was the ascomycete Exophiala jeanselmei, which was able to grow on 55 of the compounds tested (Middelhoven, 1993). More recently, studies undertaken in different laboratories led to the conclusion that the biodegradation of non-oxygenated substituted benzenes is a relatively widespread characteristic among different Exophiala species. Exophiala jeanselmei, Exophiala lecanii-corni, and the new species Exophiala oligopserma have all been found in gasphase biofilters fed either toluene or styrene, respectively, in The Netherlands ( Hartmans et al., 1990, Cox et al., 1996a and Cox et al., 1997), the United States ( Woertz et al., 2001), and Spain ( Estévez et al., 2004). The range of compounds that can be used as carbon and energy sources depends on the specific species or strain.

The ability of E. jeanselmei to grow on substituted benzenes is limited to a narrow range of substrates ( Table 3). That organism is able to grow on styrene in a mineral medium, but it cannot metabolize benzene or alkylbenzenes like toluene, ethylbenzene, or the xylene isomers ( Cox et al., 1996a). It can also grow on solidified synthetic medium with styrene as sole carbon and energy sources at concentrations of up to $25 \mathrm{~g} / \mathrm{m}^{3}$ air. In a similar context, a recently isolated E. oligosperma strain was also shown to use a very narrow range of benzene compounds ( Table 3). That organism is able to grow on toluene in the same mineral medium as E. jeanselmei, either in shake flasks or on agar plates at $30^{\circ} \mathrm{C}$ ( Estévez et al., 2004). Nevertheless, so far that strain was unable to grow on either benzene, ethylbenzene or xylenes, under the same experimental conditions as with toluene (unpublished data). At least $60-70 \%$ of the carbon source was converted to carbon dioxide, in both E. jeanselmei and $E$. oligosperma in shake flasks. It is interesting to note that the E. jeanselmei strain described by Cox et al. (1993) was recently redefined as E. oligosperma ( de Hoog et al., 2003). However, that organism is unable to assimilate toluene, contrary to the $E$. oligosperma strain described by Estévez et al. (2004). Growth experiments undertaken with another pure Exophiala strain T4, identified only at the genus level, indicated that organism used both toluene and ethylbenzene as carbon and energy sources. Benzene, naphthalene, xylenes and styrene did not support growth (Prenafeta-Boldú et al., 2001). Toluene was assimilated slightly faster than ethylbenzene. Another strain, E. lecaniicorni, was isolated on toluene as single carbon source ( Woertz et al., 2001). Later, it appeared also to be able to grow on styrene, benzene and ethylbenzene ( Qi et al., 2002). 
Table 3. Growth of different Exophiala species on non-oxygenated aromatic hydrocarbons relevant in air pollution control

\begin{tabular}{|c|c|c|c|c|}
\hline & \begin{tabular}{|l} 
Exophiala \\
jeanselmei $^{\text {a }}$ \\
\end{tabular} & $\begin{array}{l}\text { Exophiala }^{\text {lecanii-corni }^{\text {b }}} \\
\end{array}$ & \begin{tabular}{|l}
$\begin{array}{l}\text { Exophiala } \\
\text { oligosperma }^{c}\end{array}$ \\
\end{tabular} & $\begin{array}{l}\text { Exophiala } \\
\text { sp. T4 d }\end{array}$ \\
\hline Styrene & + & + & NR & - \\
\hline Benzene & - & + & - & - \\
\hline Toluene & - & + & + & + \\
\hline Ethylbenzene & - & + & - & + \\
\hline$O$-Xylene & - & NR & - & - \\
\hline$m$-Xylene & - & NR & - & - \\
\hline$p$-Xylene & - & NR & - & - \\
\hline
\end{tabular}

+, growth; -, no growth; NR, not reported.

a

Cox et al. (1996a).

b

Woertz et al. (2001).

C

Estévez et al. (2004).

d

Prenafeta Boldú et al. (2001).

Most Exophiala strains are mesophilic. In the vast majority of published papers, growth was studied either at room temperature or around $25-30^{\circ} \mathrm{C}$. E. oligosperma and Exophiala T4 were unable to assimilate toluene at temperatures above $37^{\circ} \mathrm{C}$. Both strains grow at temperatures ranging from 20 to $30^{\circ} \mathrm{C}$, with an optimum temperature for growth on toluene around $30^{\circ} \mathrm{C}$ ( Prenafeta-Boldú et al., 2001 and Estévez et al., 2004). Since they are unable to grow at the typical temperature of human body, they should not cause infections in humans or mammals in general. A similar trend was observed in $E$. jeanselmei. That organism exhibited basically constant styrene oxidation rates between 22.5 and $33^{\circ} \mathrm{C}$, whereas a rapid decrease was observed at higher temperatures ( Cox et al., 1997). Oxygen uptake rates with that strain in presence of styrene were constant between $\mathrm{pH} 1.5$ and 8. A decrease of activity was only observed, when further decreasing the $\mathrm{pH}$ value. The maximal styrene degradation rate was $21 \mu \mathrm{g} / \mathrm{mg}$ protein.min. The $K_{\mathrm{s}}$ for styrene was below $7.5 \mu \mathrm{M}$ corresponding to $0.117 \mathrm{~g} / \mathrm{m}^{3}$ air, although its exact value was not estimated. According to the Haldane equation, the inhibition constant was $0.21 \mathrm{mM}$, which is equivalent to $3.25 \mathrm{~g} / \mathrm{m}^{3}$ air.

The nature of the nitrogen source is important when working with pure fungal cultures and may be used as a criterium for the classification of yeasts and fungi. Most fungi can use ammonium as nitrogen source. Contrary to some other fungi, Exophiala species are also able to assimilate nitrate. Growth rates and yields are often lower with nitrate than with ammonium. Media containing ammonium rather than nitrate will lead to a stronger medium acidification during fungal growth. In presence of $\mathrm{NH}_{4} \mathrm{Cl}$ or $\left(\mathrm{NH}_{4}\right)_{2} \mathrm{SO}_{4}$, ammonia nitrogen is used by the fungi, and either hydrogen chloride or hydrogen sulphide is released with the simultaneous acidification of the medium. 
According to Cox et al. (1996b), styrene metabolism in E. jeanselmei starts with the attack of the vinyl side chain and the formation of phenylacetic acid, which is then hydroxylated to homogentisic acid to be finally mineralized to water and carbon dioxide. Similar metabolic reactions may be expected for toluene, with an initial reaction at the level of the methyl group resulting in the formation of benzyl alcohol and then benzoic acid before mineralization. It was observed that in other fungi as Mortierella isabellina and Helminthosporium the metabolism of toluene is also characterized by the hydroxylation of the side chain leading to the formation of benzyl alcohol ( Holland et al., 1988). As will be described below, the same holds for most of the fungi described in this paper.

\subsection{Scedosporium spp.}

The isolation of Scedosporium apiospermum from a gas-phase biofilter degrading toluene has been described on one occasion as well as its inoculation in such systems ( García-Peña et al., 2001). S. apiospermum is an ascomycete belonging to the family of Microascaceae. Although Scedosporium spp. were already known to oxidize aliphatic pollutants as hydrocarbons (n-alkanes) and alcohols ( Onodera et al., 1989b and Onodera and Ogasawara, 1989c), their ability to assimilate toluene had not been described before. Their maximum growth temperature may occasionally reach $40{ }^{\circ} \mathrm{C}$. Some strains of $S$. apiospermum have proven to be the responsible agent of cystic fibrosis ( Cimon et al., 2000) and cutaneous infections but mainly in immunosuppressed patients ( Chaveiro et al., 2003). The removal of other alkylbenzenes or hydrophobic VOCs in general has not been described.

\subsection{Paecilomyces spp.}

As in the case of $S$. apiospermum, one strain of Paecilomyces variotii has been isolated from a gas-phase biofilter and that organism has been used as inoculum in a biofilter fed toluene-polluted air ( Estévez et al., 2004). The genus Paecilomyces is closely related to the genus Penicillium, but the colonies of the former are usually white to yellow-brown, while those of Penicillium are most often green or blue-green. It was also recently reported that strains of $P$. variotii can grow on diesel oil in aqueous phase ( Bento and Gaylarde, 2001). Diesel oil is a complex mixture of hydrocarbons consisting of about $30 \% n$-alkanes, $45 \%$ cyclic alkanes and $24 \%$ aromatics ( Frankenberger et al., 1989). However, the authors did not check the nature of the specific oil components used by the fungus. It is not clear if they grew on either the aliphatic or the aromatic fraction of oil, or both. Some Paecilomyces strains are resistant to heavy metals, and lead tolerant Paecilomyces species have been used in bioremediation studies for the biosorption of heavy metals ( Wise, 1997). Although Paecilomyces spp. are deuteromycetes and do not belong to the group of white-rot fungi, it is worth mentioning that some strains are able to degrade lignin and lignin-related aromatic compounds as well ( Kluczek-Turpeinen et al., 2003). A strain of Paecilomyces, isolated from a coastal marine environment and identified at the genus level, was able to grow on $n$-alkylbenzenes provided that the side chain contained at least four carbons ( Fedorak and Westlake, 1986). It could not grow on benzene, toluene or ethylbenzene. The transient accumulation and subsequent removal of benzoic and phenyl acetic acids suggests that Paecilomyces strain initially attacked the $n$-alkyl side chain and also metabolized the aromatic ring ( Fedorak and Westlake, 1986). The $P$. variotii strain isolated in our laboratory used toluene as sole carbon and energy source in a mineral medium, with production of carbon dioxide. Our 
on-going studies indicate that it is unable to metabolize benzene, ethylbenzene or xylenes as single substrates. Toluene was degraded with ammonium as nitrogen source but not with nitrate. No transient accumulation of intermediate products was detected in that strain. Biodegradation of alkylbenzenes does usually start with the hydroxylation of the side chain. Biodegradation of benzene, without any side chain, has not been detected in Paecilomyces strains. Nevertheless, P. lilanicus SBUG-M 1093 was recently shown to partly metabolize biphenyl, a molecule containing two benzene rings without any side-chain, by a first hydroxylation step of one of the benzene rings to form 2-, 3-, and 4-hydroxybiphenyls ( Gesell et al., 2001).

Some Paecilomyces strains are thermotolerant and may grow at temperatures above 45$50{ }^{\circ} \mathrm{C}$. However, our $P$. variotii strain could not assimilate toluene at such high temperatures. Either Paecilomyces may grow in the form of pellets or its growth may be characterized by a typical filamentous hyphal aspect ( Sinha et al., 2001). It was observed that in Paecilomyces japonica the formation of pellets rather than free mycelia is favoured by high aeration and optimal substrate concentration, as well as mild agitation in aqueous phase ( Sinha et al., 2001). Paecilomyces spp. are normally not considered as pathogens and are seldom responsible for human infections, although they may occasionally be involved in mycosis in immunosuppressed patients.

\subsection{Cladosporium spp.}

Although the growth on volatile aliphatic hydrocarbons as $n$-alkanes by deuteromycetes belonging to the genus Cladosporium was reported several years ago ( Siporin and Cooney, 1975, Lindley and Heydeman, 1983 and Lindley and Heydeman, 1986), the isolation and detailed study of strains growing on aromatic pollutants is much more recent. Several years ago, it was mentioned that Cladosporium sphaerospermum ATCC 22711 exhibited a low growth on benzene as well as $o$ - and $m$-xylenes, although no further information was given ( Cofone et al., 1973). More recently, similar results were obtained with C. sphaerospermum ATCC 200384, exhibiting a limited growth on benzene at room temperature between $\mathrm{pH} 3.5$ and 6.5 ( Qi et al., 2002). That strain could also grow on toluene and ethylbenzene. No data were reported for the xylene isomers. The levels of biodegradation and/or mineralization were not evaluated in any of those experiments.

A few years ago, a strain of $C$. sphaerospermum was isolated from a gas-phase biofilter treating toluene-polluted air ( Weber et al., 1995). When grown in static-liquid medium in presence of about $40 \mu \mathrm{mol}$ toluene, the fungus started degrading the carbon source after a lag phase of about one week. More than $60 \%$ of the substrate was recovered as carbon dioxide, while approximatly $30-40 \%$ was calculated to be converted to biomass ( Prenafeta-Boldú et al., 2001). The optimum temperature for growth was $30^{\circ} \mathrm{C}$, although substrate consumption was possible over all the temperature range tested, i.e. $20-37^{\circ} \mathrm{C}$. When grown on toluene at $30^{\circ} \mathrm{C}$, the $K_{\mathrm{m}}$ value was $22 \mu \mathrm{M}$ according to oxygen consumption rates, and the $K_{\mathrm{I}}$ causing $50 \%$ inhibtion was $2.9 \mathrm{mM}$. $C$. sphaerospermum did also grow on ethylbenzene, styrene, phenol and cresols, though at much lower rates than on toluene. In that organism, there was evidence that toluene is most probably degraded by an initial attack of the methyl group, leading to the formation of benzyl alcohol, benzaldehyde, and benzoic acid before ring fission ( Weber et al., 1995). 


\subsection{Cladophialophora spp.}

Cladophialophora has a high taxonomic affinity with Exophiala ( de Hoog et al., 1995). Two different strains of that genus have been isolated on toluene, one of which was also able to grow on both styrene and ethylbenzene ( Prenafeta-Boldú et al., 2001). The fact that the other one could only grow on toluene again indicates that biodegradation of such compounds in fungi is often a species- or even strain-specific characteristic. The strain that grew on the widest substrate range, known as Cladophialophora sp. ATCC MYA-2335, was further studied in batch assays and appeared to co-metabolize the $o$ and $m$-xylenes in mixture with toluene and ethylbenzene as sources of carbon and energy ( Prenafeta-Boldú et al., 2002). The ortho- and meta-xylene isomers started being degraded after toluene and ethylbenzene were partly removed from the aqueous medium. Both isomers were completely removed from the medium in mixture with anyone of the other mentioned alkylbenzenes but they were not degraded at all, when supplied as single carbon substrate. $p$-Xylene was only degraded in a binary mixture with toluene, after complete mineralization of toluene. It was not biodegraded in presence of ethylbenzene. Only $58 \pm 12 \%$ of the xylene isomer had been degraded before concluding the experiment. About two-third of the substrate was converted to carbon dioxide in the case of either toluene or ethylbenzene, while the remaining onethird was converted to biomass ( Prenafeta-Boldú et al., 2002). Accumulation of nonidentified soluble intermediate metabolites did only occur in case of the xylenes, with accumulation of dibenzoic acids. Regarding the biodegradation pathway, it was observed that toluene is first hydroxylated at the level of the side chain to form benzyl alcohol, which is then converted to benzoic acid, prior to cleavage of the aromatic ring as was also suggested in the case of Cladosporium, Paecilomyces, and Exophiala spp.

\subsection{Other strains}

Isolates of Penicillium, Beauvaria, and Verticillium species were able to grow on alkylbenzenes provided the side chain contained at least eight (Verticillium) or nine (Penicillium, Beauvaria) carbons ( Fedorak and Westlake, 1986). All these organisms were unable to grow either on benzene or alkylbenzenes with shorter side chains, as toluene or ethylbenzene.

Besides, it is not unusual that some strains isolated on specific volatile pollutants lose their ability to biodegrade the original substrate during the harvesting procedure. This was the case, for example, for a strain of Trichosporon beigelii isolated on toluene from a gas-phase biofilter ( Veiga et al., 1999), as well as for a Pseudorotium sp. and a Leptodontium sp. ( Prenafeta-Boldú et al., 2001). With respect to the Trichosporon strain, to our knowledge, only one other previous study mentioned the use of toluene as carbon source for growth by a strain of Trichosporon cutaneum, although no further details were given ( Neujahr and Varga, 1970). In another paper, a strain of T. cutaneum KUY-6A was reported to grow on benzoic acid, a potential metabolite of alkylbenzene biodegradation in fungi ( Hasegawa et al., 1990). 


\section{Fungal bioreactors for air pollution control}

\subsection{Biofiltration with white-rot fungi}

Two different research lines may be considered in the biofiltration of VOC-polluted air with fungal biocatalysts, one focusing on the use of white-rot fungi and the other one focusing on fungi and yeast-like fungi that do not belong to the group of ligninolytic organisms. The first studies on the use of fungi in biofilters started hardly more than a decade ago. At that time, several research groups were actively evaluating the potential application of ligninolytic strains, mainly P. chrysosporium, in bioremediation of soil and water systems contaminated with polycyclic-aromatic hydrocarbons and phenolic compounds. Although white-rot fungi are of interest in the biodegradation of highmolecular-weight aromatic compounds, they appeared also to be able to remove more volatile pollutants. The production of aerial hyphae was expected to be favourable for mass transfer and biodegradation of hydrophobic contaminants in gas-phase biofilters. Results on the fungal biofiltration of polluted air were initially reported for biofilters inoculated with the species $P$. ostreatus ( Braun-Lüllemann et al., 1992). The components of a mixture of styrene, $\alpha$-pinene, alcohols $\left(\mathrm{C}_{1}-\mathrm{C}_{4}\right)$, ammonia and sulphur compounds were completely degraded ( $>99 \%$ ) by that white-rot fungus, except for $\alpha$ pinene (about 20\%). In those first studies, no data were given on the period required for start-up nor on the long-term stability of the biofilter. The system could withstand fluctuations in concentration and its efficiency was not affected by shut down periods. Since biodegradation of volatile pollutants in ligninolytic organisms is most often by a secondary metabolism, the biofilter was packed with a lignocellulosic wood-related support material, which could be used as primary carbon source. Information on the long-term behaviour of such systems would be necessary, since it can be hypothesized that a fast-pressure drop increase should be observed as a result of the biodegradation of the organic filter bed combined to the filamentous growth of the organism. More recently, different research groups have shown that mixtures of benzene, toluene, ethylbenzene and xylenes (BTEX) are also degraded efficiently by white-rot fungi in gas-phase biofilters ( Braun-Lüllemann et al., 1995 and Oh et al., 1998). In one study, inert filter beds were used in a biofilter inoculated with $P$. chrysosporium and it was claimed that the supply of an additional carbon source was not necessary ( Oh et al., 1998). It is worth recalling that the biodegradation of BTEX compounds in $P$. chrysosporium is not linked to the ligninolytic activity and that these pollutants are biodegraded during primary metabolism ( Yadav and Reddy, 1993). According to the reported experimental procedure, no nitrogen source nor other nutrients seem to have been added either during the one month experimental period, although a rich medium containing the pure strain was fed initially to inoculate the biofilter ( Oh et al., 1998). Elimination capacities between 0.5 and $10 \mathrm{~g} / \mathrm{m}^{3} \mathrm{~h}$ were reached, which are low values compared to other fungal- and bacterial-biofilters. Further research would be necessary to check the viability of inoculating white-rot fungi in gas-phase biofilters and the longterm performance and stability of such bioreactors. However, very few papers have been published on those systems over the past ten years.

\subsection{Biofiltration with Exophiala spp.}

The suggestion that white-rot fungi may be attractive for biofiltration studies because of their resistance to extreme environmental conditions and because of their filamentous structure was followed by the search and discovery of new fungal strains with similar 
characteristics and being able to use volatile aromatic hydrocarbons as sole source of carbon and energy, with the formation of carbon dioxide and water as end products. These recently isolated strains have been described above. Another incentive to undertake such studies with new fungi was the observation that when bacterial populations are gradually overgrown by fungal populations in biofilms, the performance of biofilters treating hydrophobic pollutants as toluene does sometimes improve (Veiga and Kennes, 2001). As mentioned earlier, the most extensively studied genus is Exophiala, which has almost become a model organism in the biofiltration of substituted benzenes. The first experiments were performed with a reactor packed with perlite, containing a strain of the fungus E. jeanselmei as dominant population and treating styrene polluted air ( Cox et al., 1996a and Cox et al., 1997). Occasionally, between once and twice a month, a nutritive aqueous solution was added with ammonium as the nitrogen source. Maximum elimination capacities around $62 \mathrm{~g} / \mathrm{m}^{3} \mathrm{~h}$ were reported, although this value could be increased up to $91 \mathrm{~g} / \mathrm{m}^{3} \mathrm{~h}$ by artificially increasing the concentration of oxygen in air from 21 to $40 \%$. Interestingly, similar experiments undertaken with a pure culture of E. oligosperma in a biofilter with perlite as support material and ammonium as the nitrogen source, but with toluene as carbon source led to similar elimination capacities, around $77 \mathrm{~g} / \mathrm{m}^{3} \mathrm{~h}$, under steady-state conditions ( Estévez et al., 2004). Contrary to all previously reported work, in the latter experiment $E$. oligosperma was inoculated as single pure culture in the biofilter and it was checked over a period of several months that no other fungal nor bacterial organism became dominant in the system ( Fig. 1) ( Estévez et al., 2004). In the few other reported studies, a mixed culture containing a strain of Exophiala sp. was usually present in the biofilter ( Cox et al., 1997 and Woertz et al., 2001). In the case of E. lecanii-corni, present in a biofilter fed toluene-polluted air and packed with silicate pellets, similar elimination capacities were again obtained. Moreover, that strain was shown to tolerate high-shock loads during which the elimination capacity reached up to $270 \mathrm{~g} / \mathrm{m}^{3} \mathrm{~h}$ for a short period of a few hours, although the elimination efficiency dropped from $>99 \%$ to about $90 \%$ ( Woertz et al., 2001). Previously, other authors had also reported a good tolerance of fungal populations to fluctuating pollutant concentrations in biofilters containing the fungus E. jeanselmei ( Kraakman et al., 1997). Long-term performance of the biofilter containing E. lecanii-corni was not evaluated at such high loads. In all studies undertaken with Exophiala spp. ammonium was supplied as nitrogen source and $\mathrm{pH}$ dropped as a result of the uptake of $\mathrm{NH}_{3}$. Nevertheless, in most cases $\mathrm{pH}$ values as low as 3 did not adversely affect biofilter performance. 


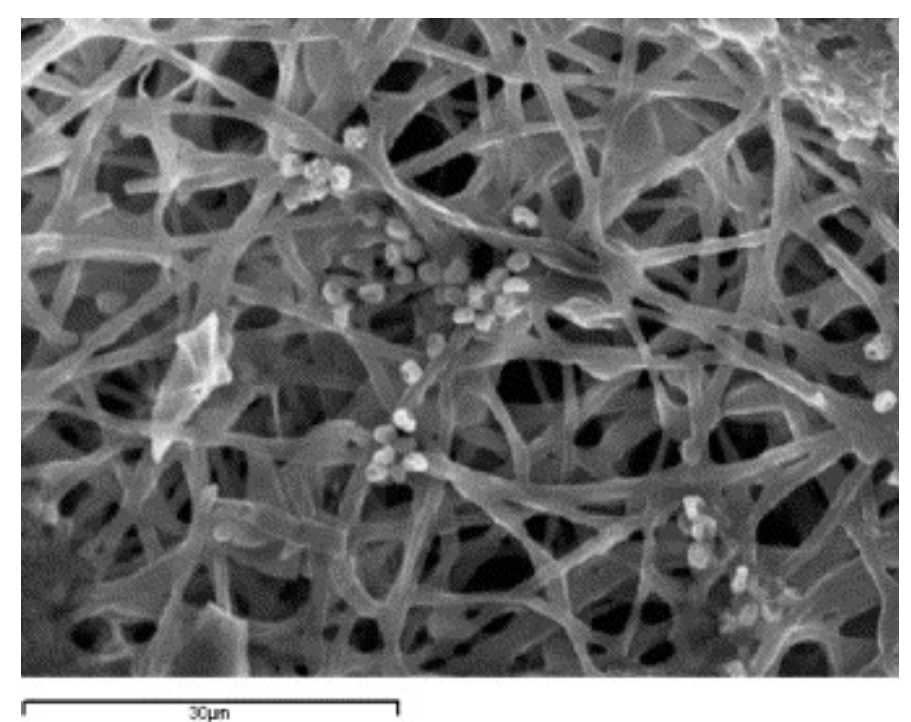

Fig. 1.

S.E.M. photograph of carrier material obtained after several months of operation from a biofilter treating toluene-polluted air and inoculated with a pure culture of Exophiala oligosperma.

In the biofilter containing the fungus E. jeanselmei and treating styrene polluted air ( Cox et al., 1997), a near homogenous biofilm thickness was observed between the inlet and the outlet of the reactor $(240-280 \mu \mathrm{m})$, while a non-homogenous biomass distribution was found in the biofilter inoculated with E. oligosperma ( Estévez et al., 2004). In the latter system, the biofilm was up to five times thicker near the inlet than near the outlet of the biofilter after six months of operation. A non-homogenous biomass distribution was also hypothesized in the biofilter containing E. lecanii-corni because of the uneven-biodegradation profile observed along the height of the reactor, despite using a directionally-switching mode of operation. The relatively fast clogging after a few months of operation at high loads is a common characteristic shared by all the biofilters containing Exophiala spp. or any other filamentous fungi in general. The addition of mites by the biofilter operator may help controling excessive fungal growth and pressure drop ( van Groenestijn et al., 2001). Other physical or chemical biomass removal strategies may be considered as well (Kennes and Veiga, 2002 and Mendoza et al., 2004). Sometimes, the natural invasion of mites was also observed in biofilters containing fungi as dominant biocatalyst, allowing to maintain at the same time a minimal pressure drop and a high efficiency for several months ( Prado et al., 2002).

\subsection{Biofiltration with other filamentous fungi}

Very few papers have described the use of other fungi in biofilters used for the treatment of hydrophobic pollutants. In some recent studies, biofilters have been inoculated either with Scedosporium apiospermum ( García-Peña et al., 2001), Paecilomyces variotii ( Estévez et al., 2004) or a Cladophialophora strain ( Woertz et al., 2002). In experiments undertaken with biofilters inoculated with a pure culture of $S$. apiospermum, toluene elimination capacities around $60-80 \mathrm{~g} / \mathrm{m}^{3} \mathrm{~h}$ could be maintained for several weeks, although all experiments were performed for short periods of less than two months. Performance data were quite variable with time and seemed to be strongly affected by a decrease of the water content and/or a lack of nutrients. Similar results were obtained with either vermiculite or a mixture of vermiculite and activated carbon as filter beds. Between 43 and $45 \%$ of the inlet toluene was converted to carbon 
dioxide and 5-7\% was incorporated as biomass. It was suggested that the non-recovered carbon could be converted into intermediates, extracellular polymers or carbonate ( García-Peña et al., 2001). Occasionally, an average elimination capacity of $258 \mathrm{~g} / \mathrm{m}^{3} \mathrm{~h}$ was reached during an almost two-week period with a mixture of activated carbon and vermiculite as packing material, although such a high performance could not be maintained and the elimination capacity rapidly dropped to $60 \mathrm{~g} / \mathrm{m}^{3} \mathrm{~h}$. Efforts made afterwards to recover and reproduce such high performance values were unsuccessful.

In the studies with $P$. variotii a biofilter was packed with perlite and fed toluenepolluted air. That organism may grow either in the form of free mycelia or pellets in aqueous phase. The presence of many pellets in the suspension used for inoculation led to a rather uneven-biomass distribution along the bed height after inoculation. This resulted in a quite slow start-up phase. Therefore, growth in the form of pellets should be avoided, when preparing a seed culture. A maximum elimination capacity around $60 \mathrm{~g} / \mathrm{m}^{3} \mathrm{~h}$ was reached with a weekly addition of an aqueous nutrient solution containing ammonium as nitrogen source ( Estévez et al., 2004).

In two biofilters inoculated with a Cladophialophora sp., elimination capacities around $70 \mathrm{~g} / \mathrm{m}^{3} \mathrm{~h}$ were reached with removal efficiencies close to $100 \%$, when using perlite as carrier material and feeding an aqueous nutrient solution once a week. After two and a half months operation, the elimination capacity increased to $120 \mathrm{~g} / \mathrm{m}^{3} \mathrm{~h}$ in the biofilter in which mites had been added to the filter bed on day 32, while the elimination capacity dropped and stabilized around $50 \mathrm{~g} / \mathrm{m}^{3} \mathrm{~h}$ in the absence of mites (Woertz et al., 2002). It is worth observing that in a third biofilter packed with polyurethane foam and operated under the same conditions, elimination capacities around $120 \mathrm{~g} / \mathrm{m}^{3} \mathrm{~h}$ were also reached without the need of adding mites to that reactor throughout the four months operating period.

Biofilter performance has also been reported for non-defined mixed populations in which fungi were clearly dominant in the biofilm, in co-cultutre with acidophilic bacteria. In one such biofilter fed a mixture of toluene, ethylbenzene and $o$-xylene, the elimination capacity reached $120 \mathrm{~g} / \mathrm{m}^{3} \mathrm{~h}$ with the complete removal of the pollutants, i.e. 100\% removal efficiency ( Veiga and Kennes, 2001). Performance data of biofilters in which the dominant populations of the biocatalyst are either bacteria, fungi or mixed populations are compared in Table 4. These data indicate that good results have been obtained both with bacterial and fungal biocatalysts. However, under optimial conditions, the best results seem to be reached with mixed fungal-bacterial populations in which fungi are dominant. In such a case, studies with benzene-compounds (alquilbenzenes, styrene) indicated that elimination capacities as high as 120$140 \mathrm{~g} / \mathrm{m}^{3} \mathrm{~h}$ with removal efficiencies exceeding 99\%, could be maintained for long periods under stable operating conditions ( Paca et al., 2001 and Veiga and Kennes, 2001). Similarly, in biofilters packed with polyurethane and fed $\alpha$-pinene, elimination capacities around $38 \mathrm{~g} / \mathrm{m}^{3} \mathrm{~h}$ were reached when fungi were dominant in the biofilm ( van Groenestijn and Liu, 2002), which is a very good result compared to previously published work in which bacteria were most often dominant. 
Table 4.

Examples of high performance biofilters treating benzene compounds and containing either fungi, bacteria or both populations as dominant biocatalysts

\begin{tabular}{|c|c|c|c|c|c|}
\hline Pollutant(s) & Inoculum & $\begin{array}{l}\text { Dominant } \\
\operatorname{organism}(s)^{\text {a }}\end{array}$ & Carrier material & \begin{tabular}{|l|} 
Maximum \\
E.C.
\end{tabular} & References \\
\hline TEX & $\begin{array}{l}\text { Non defined mixed } \\
\text { culture }\end{array}$ & Bacteria $^{c}$ & Perlite & 70 & $\begin{array}{|lll|}\begin{array}{l}\text { Veiga } \\
(1997)\end{array} & \text { et } & \text { al. } \\
\end{array}$ \\
\hline TEX & $\begin{array}{l}\text { Consortium: } 2 \\
\text { bacteria }+1 \text { fungus }\end{array}$ & Bacteria & Perlite & 72 & \begin{tabular}{|lr} 
Veiga & and \\
Kennes (2001)
\end{tabular} \\
\hline $\mathrm{TX}$ & $\begin{array}{l}\text { Consortium: } \quad 4 \\
\text { bacteria }\end{array}$ & NS & Peat beads & 115 & $\mid \begin{array}{lll}\text { Jorio } & \text { et } & \text { al. } \\
(1998) & & \end{array}$ \\
\hline Toluene & \begin{tabular}{|ll} 
Consortium: & 4 \\
bacteria & \\
\end{tabular} & NS & Peat beads & $\begin{array}{|ll|}165 & (\mathrm{RE} \\
71 \%) & \\
\end{array}$ & $\begin{array}{|lll|}\begin{array}{l}\text { Jorio } \\
(1998)\end{array} & \text { et } & \text { al. } \\
\end{array}$ \\
\hline Toluene & None & \begin{tabular}{|l} 
Pseudomonas \\
putida
\end{tabular} & Compost pellets & 200 & $\begin{array}{|lll|}\begin{array}{l}\text { Roy et } \\
(2003)\end{array} & \text { al. } \\
\end{array}$ \\
\hline Toluene & Acinetobacter sp. & NS & \begin{tabular}{|l|} 
Peat:Glass beads \\
$(4: 1)$
\end{tabular} & 100 & $\begin{array}{|lll|}\begin{array}{l}\text { Zilli et } \\
(2000)\end{array} & \\
\end{array}$ \\
\hline TEX & $\begin{array}{l}\text { Consortium: } 2 \\
\text { bacteria }+1 \text { fungus }\end{array}$ & \begin{tabular}{|lr||} 
Fungi: & non \\
inoculated strains
\end{tabular} \mid & Perlite & $>120$ & \begin{tabular}{|lr} 
Veiga & and \\
Kennes (2001)
\end{tabular} \\
\hline Toluene & $\begin{array}{l}\text { Bacteria: mainly } \\
\text { Pseudomonas } \\
\text { putida } \\
\end{array}$ & $\begin{array}{l}\text { Exophiala } \\
\text { lecanii-corni }\end{array}$ & Silicate pellets & $\left|\begin{array}{l}70-90, \quad 270 \\
\text { (short term) }\end{array}\right|$ & $\begin{array}{l}\text { Woertz et al. } \\
(2001)\end{array}$ \\
\hline Toluene & $\begin{array}{l}\text { Scedosporium } \\
\text { apiospermum }\end{array}$ & \begin{tabular}{|l} 
Scedosporium \\
apiospermum
\end{tabular} & $\begin{array}{l}\text { GAC:Vermiculite } \\
(15: 85)\end{array}$ & \begin{tabular}{|l|}
$\begin{array}{l}60-80, \\
\text { (short term) }\end{array}$ \\
\end{tabular} & \begin{tabular}{|l|}
$\begin{array}{l}\text { García-Peña et } \\
\text { al. (2001) }\end{array}$ \\
\end{tabular} \\
\hline Toluene & \begin{tabular}{|l|} 
Exophiala \\
oligosperma \\
\end{tabular} & $\begin{array}{l}\text { Exophiala } \\
\text { oligosperma }\end{array}$ & Perlite & $>70$ & \begin{tabular}{|l}
$\begin{array}{l}\text { Estévez et al. } \\
(2004)\end{array}$ \\
\end{tabular} \\
\hline Toluene & \begin{tabular}{|l} 
Paecilomyces \\
variotii \\
\end{tabular} & $\begin{array}{l}\text { Paecilomyces } \\
\text { variotii }\end{array}$ & Perlite & 60 & \begin{tabular}{|l} 
Estévez et al. \\
$(2004)$
\end{tabular} \\
\hline Styrene & $\begin{array}{l}\text { Mixed culture with } \\
\text { E. jeanselmei }\end{array}$ & E. jeanselmei & Perlite & 62 & $\begin{array}{|lrr|}\begin{array}{l}\text { Cox et al. } \\
(1997)\end{array} & \\
\end{array}$ \\
\hline Styrene & NS & Bacteria + fungi & Perlite & 140 & \begin{tabular}{|ll} 
Paca et al. \\
$(2001)$
\end{tabular} \\
\hline
\end{tabular}

T: toluene, E: ethylbenzene, X: xylene(s), NS: not specified, GAC: granular activated carbon.

Found in the biofilter after several weeks/months operation.

b

Removal efficiencies (RE) $>90 \%$, unless otherwise stated.

Ratio (cfu bacteria/cfu fungi) $=3.75$. 


\subsection{Conclusions and future trends}

The first studies devoted to the biofiltration of volatile hydrophobic pollutants with fungal biocatalysts were published about one decade ago. Most of the research work has been focused on alquilbenzenes. Several conclusions can be drawn from the so far reported data.

Among the few fungal strains isolated so far, the organisms belonging to the genus Exophiala are the dominant ones.

As might have been expected from the typical physiological characteristics of these eukaryotes, fungal-biofilters can cope more efficiently than most bacterialbiofilters with low moisture levels and acidification. As a general rule, it may be concluded that whenever the $\mathrm{pH}$ does not drop below approximately 3 , the biofilter's performance will be hardly affected, although the threshold value will depend on the specific organisms present in the biofilm. The influence of the moisture content has not been quantified accurately. However, if drying out is significant, this will also become an important issue in fungal biofilters.

In most studies in which one specific species was dominant in the biofilter, maximum elimination capacities around $70-90 \mathrm{~g} / \mathrm{m}^{3} \mathrm{~h} \quad(>95 \%$ removal efficiency) were obtained in the best cases, under steady-state conditions, for different benzene-compounds, which are highly satisfactory results compared to most bacterial-biofilters. Despite these encouraging data, the hypothesis that the performance should improve in presence of filamentous fungi because of the enhanced mass transfer, still needs to be confirmed scientifically in future research.

Unusually high elimination capacities of $200-250 \mathrm{~g} / \mathrm{m}^{3} \mathrm{~h}$ have occasionally been reached in fungal-biofilters. However, such high values could only be maintained during short-term experiments and/or under non-steady-state conditions. Future research should allow defining how to maintain such a high performance for long periods, under stable conditions.

According to the literature, the best results were obtained in biofilters in which mixed bacterial-fungal populations were present with fungi as the dominant species. Under such conditions, in biofilters fed benzene-compounds, elimination capacities of $120-140 \mathrm{~g} / \mathrm{m}^{3} \mathrm{~h}$ (RE > 95\%) could be maintained under stable, relatively long operating conditions, even at a low $\mathrm{pH}$ around 3. 
The few isolated fungi can only metabolize a quite narrow range of pollutants compared to most bacteria. Therefore, future research should also focus on the isolation and identification of new fungi with a broader substrate spectrum.

The filamentous growth of fungi favours fast clogging, which would lead to a gradual drop of the reactor's performance over time. The controlled addition of mites has proven to slow down clogging phenomena. Nevertheless, further research is still needed in order to evaluate and optimize biological, physical and chemical alternatives to reduce head losses.

The potential pathogenecity of some fungal strains is another key issue that certainly needs to be investigated in biofiltration studies, but that has been somewhat overlooked by engineers.

\section{Acknowledgements}

Part of our research data included in this paper were obtained, thanks to funds from the Spanish Ministry of Science and Technology.

\section{References}

R.M. Atlas, R. Bartha

Microbial Ecology-Fundamentals and Application

(fourth ed.)Benjamin/Cummings Publishing Co., Menlo Park, CA, USA (1998)

F.M. Bento, C.C. Gaylarde

Biodeterioration of stored diesel oil: studies in Brazil

Intern. Biodet. Biodegrad., 47 (2001), pp. 107-112

A. Braun-Lüllemann, A. Majcherczyk, N. Tebbe, A. Hüttermann

Bioluftfilter auf der Basis von Weissfäulepilzen

A.J. Dragt, J. van Ham (Eds.), Biotechniques for Air Pollution Abatement and Odour Control Policies, Elsevier, Amsterdam, The Netherlands (1992), pp. 91-95

A. Braun-Lüllemann, C. Johannes, A. Majcherczyk, A. Hüttermann

The use of white-rot fungi as active biofilters

R.E. Hinchee, R.S. Keen, G.D. Sayles (Eds.), Biological Unit Processes for Hazardous Waste Treatment, Batelle Press, Columbus, USA (1995), pp. 235-242

A. Braun-Lüllemann, A. Majcherczyk, A. Hüttermann

Biodegradation of styrene by white-rot fungi

Appl. Microbiol. Biotechnol., 47 (1997), pp. 150-155 


\section{C.E. Cerniglia}

Biodegradation of polycyclic aromatic hydrocarbons

Biodegradation, 3 (1992), pp. 351-358

M.A. Chaveiro, R. Vieira, J. Cordoso, A. Afonso

Cutaneous infection due to Scedosporium apiospermum in an immunosuppressed patient

J. Eur. Acad. Dermatol. Venereol., 17 (2003), pp. 47-48

K.-S. Cho, M. Hirai, M. Shoda

Degradation of hydrogen sulfide by Xanthomonas sp. strain DY44 isolated from peat

Appl. Environ. Microbiol., 58 (1992), pp. 1183-1189

Y.-C. Chung, C. Huang

Removal of hydrogen sulphide by immobilized Thiobacillus sp. strain CH11 in a biofilter

J. Chem. Technol. Biotechnol., 69 (1997), pp. 58-62

B. Cimon, J. Carrère, J.F. Vinatier, J.P. Chazalette, D. Chabasse, J.P. Bouchara

Clinical significance of Scedosporium apiospermum in patients with cystic fibrosis (note)

Eur. J. Clin. Microbiol. Infec. Dis., 19 (2000), pp. 53-56

L. Cofone, J.D. Walker, J.J. Cooney

Utilization of hydrocarbons by Cladosporium resinae

J. Gen. Microbiol., 76 (1973), pp. 243-246

H.H.J. Cox, J.H.M. Houtman, H.J. Doddema, W. Harder

Enrichment of fungi and degradation of styrene in biofilters

Biotechnol. Lett., 15 (1993), pp. 737-742

H.H.J. Cox, F.J. Magielsen, H.J. Doddema, W. Harder

Influence of the water content and water activity on styrene degradation by Exophiala jeanselmei in biofilters

Appl. Microbiol. Biotechnol., 45 (1996), pp. 851-856

H.H.J. Cox, B.W. Faber, W.N.M. van Heiningen, H. Radhoe, H.J. Doddema, W. Harder Styrene metabolism in Exophiala jeanselmei and involvement of a cytochrome P-450dependent styrene monooxygenase

Appl. Environ. Microbiol., 62 (1996), pp. 1471-1474

H.H.J. Cox, R.E. Moerman, S. van Baalen, W.N.M. van Heiningen, H.J. Doddema, W. Harder

Performance of a styrene-degrading biofilter containing the yeast Exophiala jeanselmei

Biotechnol. Bioeng., 53 (1997), pp. 259-266

J.S. Davies, A.M. Wellman, J.E. Zajic

Hyphomycetes utilizing natural gas

Can. J. Microbiol., 19 (1973), pp. 81-85 
M.W. Davis, J.A. Glaser, J.W. Evans, R.T. Lamar

Field evaluation of the lignin-degrading fungus Phanerochaete sordida to treat creosote-contaminated soil

Environ. Sci. Technol., 27 (1993), pp. 2572-2576

G.S. de Hoog, K. Takeo, E. Göttlich, K. Nishimura, M. Miyaji

A human isolate of Exophiala (Wangiella) dermatitidis forming a catenate synanamorph that links the genera Exophiala and Cladophialophora

J. Med. Veter. Mycol., 33 (1995), pp. 355-358

G.S. de Hoog, V. Vicente, R.B. Caligiorne, S. Kantarcioglu, K. Tintelnot, A.H.G. Gerrits van den Ende, G. Haase

Species diversity and polymorphism in the Exophiala spinifera clade containing opportunistic black yeast-like fungi

J. Clin. Microbiol., 41 (2003), pp. 4767-4778

E. Estévez, M.C. Veiga, C. Kennes

Fungal biodegradation of toluene in gas-phase biofilters.

W. Verstraete (Ed.), Proceedings of the 5th European Symposium on Environmental Biotechnology, Oostende, Belgium, 25-28 April (2004), pp. 337-340

P.M. Fedorak, D.W.S. Westlake

Fungal metabolism of $n$-alkylbenzenes

Appl. Environ. Microbiol., 51 (1986), pp. 435-437

W.T. Frankenberger, K.D. Emerson, D.W. Turner

In situ bioremediation of an underground diesel fuel spill: a case history

Environ. Manag., 13 (1989), pp. 325-332

E.I. García-Peña, S. Hernández, E. Favela-Torres, R. Auria, S. Revah

Toluene biofiltration by the fungus Scedosporium apiospermum TB1

Biotechnol. Bioeng., 76 (2001), pp. 61-69

M. Gesell, E. Hammer, M. Specht, W. Francke, F. Schauer

Biotransformation of biphenyl by Paecilomyces lilanicus and characterization of ring cleavage products

Appl. Environ. Microbiol., 67 (2001), pp. 1551-1557

L.K. Hardison, S.S. Curry, L.M. Ciuffetti, M.R. Hyman

Metabolism of diethyl ether and cometabolism of methyl tert-butyl ether by a filamentous fungus, a Graphium sp

Appl. Environ. Microbiol., 63 (1997), pp. 3059-3067

S. Hartmans, M.J. van der Werf, J.A.M. de Bont

Bacterial degradation of styrene involving a novel flavin adenine dinucleotide dependent styrene monooxygenase

Appl. Environ. Microbiol., 56 (1990), pp. 1347-1351 
Y. Hasegawa, T. Okamoto, H. Obata, T. Tokuyama

Utilization of aromatic compounds by Trichosporon cutaneum KUY-6A

J. Ferment. Bioengineer., 69 (1990), pp. 122-124

M. Hofrichter, T. Günther, W. Fritsche

Metabolism of phenol, chloro- and nitrophenols by the Penicillium strain Bi 7/2 isolated from a contaminated soil

Biodegradation, 3 (1993), pp. 415-421

M. Hofrichter, F. Bublitz, W. Fritsche

Cometabolic degradation of o-cresol and 2,6-dimethylphenol by Penicillium frequentans $\mathrm{Bi} 7 / 2$

J. Basic Microbiol., 35 (1995), pp. 303-313

H.L. Holland, F.M. Brown, B. Muñoz, R.W. Ninniss

Side chain hydroxylation of aromatic hydrocarbons by fungi. II. Isotope effects and mechanism

J. Chem. Soc. Perkins Trans., 11 (1988), pp. 1557-1563

Ishikawa et al., 1980

Ishikawa, H., Kita, Y., Horikoshi, K., 1980. US Patent 4225381.

K.H. Jones, P.W. Trudgill, D.J. Hopper

Metabolism of $p$-cresol by the fungus Aspergillus fumigatus

Appl. Environ. Microbiol., 59 (1993), pp. 1125-1130

H. Jorio, K. Kiared, R. Brzezinski, A. Leroux, G. Viel, M. Heitz

Treatment of air polluted with high concentrations of toluene and xylene in a pilot-scale biofilter

J. Chem. Technol. Biotechnol., 73 (1998), pp. 183-196

D.P. Kelly, N.A. Smith

Organic sulfur compounds in the environment

Adv. Micr. Ecol., 11 (1990), pp. 345-385

C. Kennes, J.M. Lema

Degradation of major compounds of creosotes (PAH and phenols) by Phanerochaete chrysosporium

Biotechnol. Lett., 16 (1994), pp. 759-764

C. Kennes, M.C. Veiga

Bioreactors for Waste Gas Treatment

Kluwer Academic Publishers, Dordrecht, The Netherlands (2001) (ISBN: 0-7923-71909)

Kennes and Veiga, 2002

C. Kennes, M.C. Veiga

Inert filter media for the biofiltration of waste gases - characteristics and biomass control

Rev. Environ. Sci. Biotechnol., 1 (2002), pp. 201-214 
B. Kluczek-Turpeinen, M. Tuomela, A. Hatakka, M. Hofrichter

Lignin degradation in a compost environment by the deuteromycete Paecilomyces inflatus

Appl. Microbiol. Biotechnol., 61 (2003), pp. 374-379

N.J.R. Kraakman, J.W. van Groenestijn, B. Koers, D.C. Heslinga

Styrene removal using a new type of bioreactor with fungi.

Proceedings of the International Symposium on Biological Waste Gas Cleaning, Düsseldorf, Germany, VDI Verlag (1997), pp. 225-232

N.D. Lindley, M.T. Heydeman

Uptake of vapour phase $\left[{ }^{14} \mathrm{C}\right]$ dodecane by whole mycelia of Cladosporium resinae

J. Gen. Microbiol., 129 (1983), pp. 2301-2305

N.D. Lindley, M.T. Heydeman

The uptake of $n$-alkanes from alkane mixtures during growth of the hydrocarbonutilizing fungus Cladosporium resinae

Appl. Microbiol. Biotechnol., 23 (1986), pp. 384-388

J.A. Mendoza, O.J. Prado, M.C. Veiga, C. Kennes

Hydrodynamic behaviour and comparison of technologies for the removal of excess biomass in gas-phase biofilters

Water Res., 38 (2004), pp. 404-413

W.J. Middelhoven

Catabolism of benzene compounds by ascomycetous and basidiomycetous yeasts and yeastlike fungi

Antonie van Leeuwenhoek, 63 (1993), pp. 125-144

W.J. Middelhoven, G. Scorzetti, J.W. Fell

Trichosporon guehoae sp. nov., an anamorphic basidiomycetous yeast

Can. J. Microbiol., 45 (1999), pp. 686-690

W.J. Middelhoven, G. Scorzetti, J.W. Fell

Trichosporon veenhuisii sp. nov., an alkane-assimilating anamorphic basidiomycetous yeast

Int. J. Syst. Evol. Microbiol., 50 (2000), pp. 381-387

O. Milstein, Y. Vered, L. Shragina, J. Gressel, H.M. Flowers, A. Hüttermann

Metabolism of lignin related aromatic compounds by Aspergillus japonicus

Arch. Microbiol., 135 (1983), pp. 147-154

Neujahr and Varga, 1970

H.Y. Neujahr, J.M. Varga

Degradation of phenols by intact cells and cell-free preparations of Trichosporon cutaneum

Eur. J. Biochem., 13 (1970), pp. 37-44 
E.J. Nyns, J.P. Auquiere, A.L. Wiaux

Taxonomic value of the property of fungi to assimilate hydrocarbons

Antonie van Leuwenhoek, 34 (1968), pp. 441-457

Y.-S. Oh, S.-C. Choi, Y.-K. Kim

Degradation of gaseous BTX by biofiltration with Phanerochaete chrysosporium

J. Microbiol., 36 (1998), pp. 34-38

M. Onodera, Y. Endo, N. Ogasawara

Utilization of short-chain hydrocarbons and accumulation of methylketones by a gaseous hydrocarbon assimilating mold, Scedosporium sp. A-4

Agric. Biol. Chem., 53 (1989), pp. 1431-1432

Oxidation of gaseous hydrocarbons by a gaseous hydrocarbon assimilating mold, Scedosporium sp. A-4

Agric. Biol. Chem., 53 (1989), pp. 1947-1951

M. Onodera, N. Ogasawara

Oxidation of secondary alcohols to methylketones by a gaseous hydrocarbon assimilating mold, Scedosporium sp. A-4

Agric. Biol. Chem., 53 (1989), pp. 2673-2677

J. Oudot, J. Dupont, S. Haloui, M.F. Roquebert

Biodegradation potential of hydrocarbon-assimilating tropical fungi

Soil Biol. Biochem., 25 (1993), pp. 1167-1173

J. Paca, B. Koutsky, M. Maryska, M. Halecky

Styrene degradation along the bed height of perlite biofilter

J. Chem. Technol. Biotechnol., 76 (2001), pp. 873-878

C.-G. Phae, M. Shoda

A new fungus which degrades hydrogen sulfide, methanethiol, dimethyl sulfide and dimethyl disulfide

Biotechnol. Lett., 13 (1991), pp. 375-380

O.J. Prado, J.A. Mendoza, M.C. Veiga, C. Kennes

Optimization of nutrient supply in a downflow gas-phase biofilter packed with an inert carrier

Appl. Microbiol. Biotechnol., 59 (2002), pp. 567-573

F.X. Prenafeta-Boldú, A. Kuhn, D.M.A.M. Luykx, H. Anke, J.W. van Groenestijn, J.A.M. de Bont

Isolation and characterization of fungi growing on volatile aromatic hydrocarbons as their sole carbon and energy source

Mycol. Res., 105 (2001), pp. 477-484

F.X. Prenafeta-Boldú, J. Vervoort, J.T.C. Grotenhuis, J.W. van Groenestijn

Substrate interactions during the biodegradation of benzene, toluene, ethylbenzene, and xylene (BTEX) hydrocarbons by the fungus Cladophialophora sp. strain T1

Appl. Environ. Microbiol., 68 (2002), pp. 2660-2665 
B. Qi, W.M. Moe, K.A. Kinney

Biodegradation of volatile organic compounds by five fungal species

Appl. Microbiol. Biotechnol., 58 (2002), pp. 684-689

S. Roy, J. Gendron, M.-C. Delhoménie, L. Bibeau, M. Heitz, R. Brzezinski

Pseudomonas putida as the dominant toluene-degrading bacterial species during air decontamination by biofiltration

Appl. Microbiol. Biotechnol., 61 (2003), pp. 366-373

K. Sakaguchi, R. Kurane, M. Murata

Assimilation of formaldehyde and other C1-compounds by Gliocladium deliquescens and Paecilomyces varioti

Agr. Biol. Chem., 39 (1975), pp. 1695-1702

K.M. Scow, D. Li, V.B. Manilal, M. Alexander

Mineralization of organic compounds at low concentrations by filamentous fungi

Mycol. Res., 94 (1990), pp. 793-798

K. Shinabe, S. Oketani, T. Ochi, M. Matsumura

Characteristics of hydrogen sulfide removal by Thiobacillus thiooxidans KS1 isolated from a carrier-packed biological deodorization system

J. Ferment. Bioeng., 80 (1995), pp. 592-598

J. Sinha, J.T. Bae, J.P. Park, K.H. Kim, C.H. Song, J.W. Yun

Changes in morphology of Paecilomyces japonica and their effect on broth rheology during production of exo-biopolymers

Appl. Microbiol. Biotechnol., 56 (2001), pp. 88-92

C. Siporin, J.J. Cooney

Extracellular lipids of Cladosporium (Amorphotheca) resinae grown on glucose and $n$ alkanes

Appl. Microbiol., 29 (1975), pp. 604-609

Y. Tanji, T. Kanagawa, E. Mikami

Removal of dimethyl sulfide, methyl mercaptan and hydrogen sulphide by immobilized Thiobacillus thioparus TK-m

J. Ferment. Bioeng., 67 (1989), pp. 280-285

J.W. van Groenestijn, W.N.M. van Heiningen, N.J.R. Kraakman

Biofilters based on the action of fungi

Water Sci. Technol., 44 (2001), pp. 227-232

J.W. van Groenestijn, J.X. Liu

Removal of alpha-pinene from gases using biofilters containing fungi

Atmos. Environ., 36 (2002), pp. 5501-5508 
M.C. Veiga, M. Fraga, L. Amor, C. Kennes

Microbial and kinetic characterization of biofilters degrading alkylbenzene vapors under acidic conditions.

H. Verachtert, W. Verstraete (Eds.), Proceedings of the International Symposium Environmental Biotechnology, TIV, Oostende, Belgium (1997), pp. 185-188

Veiga et al., 1999

M.C. Veiga, M. Fraga, L. Amor, C. Kennes

Biofilter performance and characterization of a biocatalyst degrading alkylbenzene gases

Biodegradation, 10 (1999), pp. 169-176

M.C. Veiga, C. Kennes

Parameters affecting performance and modeling of biofilters treating alkylbenzenepolluted air

Appl. Microbiol. Biotechnol., 55 (2001), pp. 254-258

F.J. Weber, K.C. Hage, J.A.M. de Bont

Growth of the fungus Cladosporium sphaerospermum with toluene as the sole carbon and energy source

Appl. Environ. Microbiol., 61 (1995), pp. 3562-3566

D.L. Wise

Global environmental biotechnology.

Proceedings of the Third International Symposium of the International Society for Environmental Biotechnology, Boston, USA, 15-20 July, Elsevier Publisher (1997)

J.R. Woertz, K.A. Kinney, N.D.P. McIntosh, P.J. Szaniszlo

Removal of toluene in a vapor-phase bioreactor containing a strain of the dimorphic black yeast Exophiala lecanii-corni

Biotechnol. Bioeng., 75 (2001), pp. 550-558

J.R. Woertz, W.N.M. van Heiningen, M.H.A. van Eeckert, N.J.R. Kraakman, K.A. Kinney, J.W. van Groenestijn

Dynamic bioreactor operation: effects of packing material and mite predation on toluene removal from off-gas

Appl. Microbiol. Biotechnol., 58 (2002), pp. 690-694

J.S. Yadav, C.A. Reddy

Degradation of benzene, toluene, ethylbenzene, and xylenes (BTEX) by the lignindegrading basidiomycete Phanerochaete chrysosporium

Appl. Environ. Microbiol., 59 (1993), pp. 756-762

Y. Yang, E.R. Allen

Biofiltration control of hydrogen sulfide

J. Air Waste Manage. Assoc., 44 (1994), pp. 863-868 
L. Zhang, M. Hirai, M. Shoda

Removal characteristics of dimethyl sulfide, methanethiol and hydrogen sulfide by Hyphomicrobium sp. I55 isolated from a peat biofilter

J. Ferment. Bioengineer., 72 (1991), pp. 392-396

L. Zhang, I. Kuniyoshi, M. Hirai, M. Shoda

Oxidation of dimethyl sulfide by Pseudomonas acidovorans DMR-11 isolated from a peat biofilter

Biotechnol. Lett., 13 (1991), pp. 223-228

M. Zilli, A. Del Borghi, A. Converti

Toluene vapour removal in a laboratory-scale biofilter

Appl. Microbiol. Biotechnol., 54 (2000), pp. 248-254 